\title{
ORGANOLOGI ALAT MUSIK TONGKEK DI LOMBOK TIMUR
}

\author{
Hary Murcahyanto* \\ Yuspianal Imtihan ${ }^{\star * *}$ \\ Muh.Alfian Nur Khair ${ }^{* * *}$ \\ * Faculty of Language Art and Humanities, Universitas Hamzanwadi, Selong, \\ Lombok Timur, Indonesia \\ harymurcahyanto@gmail.com \\ ** Faculty of Language Art and Humanities, Universitas Hamzanwadi, Selong, \\ Lombok Timur, Indonesia \\ iyuspianal@gmail.com \\ ${ }^{* * *}$ Faculty of Language Art and Humanities, Universitas Hamzanwadi, Selong, \\ Lombok Timur, Indonesia \\ muhammadalfiannurkhair@gmail.com
}

\begin{abstract}
Organology of Tongkek musical instruments in Pancor Subdistrict Selong East Lombok Province West Nusa Tenggara has an important role to be held, this research focuses on the process of making and processing the ignition of Tongkek musical instruments. This type of research uses the descriptive qualitative method. The subject in this study is The Tongkek Craftsman. Data collection techniques used in this research are interviews, laboratory tests, and documentation. Examination of the validity of data in this study using source triangulation. Data analysis techniques used consist of four stages, namely, data collection ( data collection), reduction (data reduction), Data display (presentation of data), and Conclusion drawing/verification (examiner conclusion and verification). The results of this study contain the organology of Tongkek musical instruments in detail and detail. First, in the manufacturing process, the craftsmen pay attention to the quality of tools and materials to be used, such as the degree of dryness, thickness, the sharpness of the knife, and the diameter of the bamboo used. Second, the process of logging, the most important thing in the process of Tongkek is the sensitivity of taste in each craftsman. Good quality raw materials are also very supportive of sound quality in Tongkek. So with this research, a piece of Tongkek music will know Tongkek instruments better and understand the importance of caring for Tongkek musical instruments wisely, so that the use of Tongkek musical instruments can be used optimally and is expected to bring up the makers of Tongkek with good sound quality.
\end{abstract}

Keywords: Organology, Traditional musical instruments, Tongkek

\section{ABSTRAK}

Organologi alat musik Tongkek di Kelurahan Pancor Kecamatan Selong Kabupaten Lombok Timur Provinsi Nusa Tenggara Barat memiliki peran penting untuk diadakan, penelitian ini berfokus pada proses pembuatan dan proses penalaan alat musik 
Tongkek. Jenis penelitian ini menggunakan metode deskriptif kualitatif. Subjek dalam penelitian ini adalah Pengrajin Tongkek. Teknik pengumpulan data yang digunakan dalam penelitian ini adalah wawancara, uji laboraturium dan dokumentasi. Pemeriksaan keabsahan data dalam penelitian ini menggunakan triangulasi sumber.Teknik analisis data yang digunakan terdiri dari empat tahapan yaitu, data collection (pengumpulan data), reduction (reduksi data), Data display (penyajian data), dan Conclusion drawing/verification (pemeriksa kesimpulan dan verifikasi). Hasil penelitian ini memuat Organologi alat musik Tongkek secara detail dan terperinci. Pertama, pada proses pembuatannya para pengrajin memerhatikan kualitas alat dan bahan yang akan digunakan, seperti tingkat kekeringan, ketebalan, ketajaman pisau dan diameter bambu yang digunakan. Kedua, proses penalaannya, hal terpenting dalam proses penalaan Tongkek adalah kepekaan rasa pada setiap pengrajin. Kualitas bahan baku yang baik juga sangat menunjang kualitas bunyi pada Tongkek. Sehingga dengan adanya penelitian ini seorang sekahe musik Tongkek akan lebih mengenal alat musik Tongkek dengan lebih baik dan memahami pentingnya untuk merawat alat musik Tongkek secara bijak, agar penggunaan alat musik Tongkek bisa digunakan secara optimal serta diharapkan dapat memunculkan para pembuat Tongkek dengan kualitas bunyi yang baik.

Kata Kunci: Organologi, Alat musik tradisional,Tongkek

\section{PENDAHULUAN}

Organologi alat musik Tongkek di Kelurahan Pancor Kecamatan Selong Kabupaten Lombok Timur Provinsi Nusa Tenggara Barat memiliki peran penting untuk diadakan. Organologi alat musik mempelajari seluruh aspek fisik, terutama aspek fisik tentang sebuah alat musik.

Berdasarkan hasil observasi yang dilakukan ditemukan bahwa di Kelurahan Pancor belum banyak yang bisa membuat alat musik Tongkek. Karena pembuatan alat musik ini membutuhkan pengetahuan, keterampilan dan pengalaman yang baik. Oleh karena itu para pemain alat musik tradisi/ sekahe musik Tongkek sangatlah penting mengetahui Organologi alat musik Tongkek ini. Melalui pengetahuan tentang Organologi Tongkek tersebut, seorang sekahe musik Tongkek akan lebih mengenal alat musik Tongkek dengan lebih baik dan memahami pentingnya merawat alat musik Tongkek secara bijak, agar penggunaan alat musik Tongkek bisa digunakan secara optimal. Selain itu, diharapkan banyak bermunculan seniman pembuat Tongkek yang baru.

Tujuan penelitian ini adalah untuk mengetahui Organologi alat musik Tongkek di Kelurahan Pancor yang berfokus pada proses pembuatan dan proses penalaan alat musik Tongkek.

Kata Organologi adalah kata bentukan dari kata "organ" dan "logos", yang artinya ; organ adalah alat-alat atau bagian-bagian yang merupakan kesatuan dalam komunium, sedangkan Logos adalah IImu pengetahuan. Organologi berarti ilmu pengetahuan tentang alat-alat dalam kesatuan komunium (Hendarto, 2011). 
Organologi. Ilmu alat musik, studi mengenai alat-alat musik (bukan hanya alat musik organ (Banoe, 2003).

Tujuan Organologi mempelajari seluruh aspek instrumen, terutama aspek fisik (dengan pendekatan tekstual) tentang sebuah alat, dalam hal ini adalah alat atau instrumen musik. Bila di dalam studi itu juga menyangkut hal-hal yang kontekstual seperti misalnya sejarah, mitologi, simbol dan lainnya hanyalah merupakan kelengkaan dari apa yang dinamakan studi Organologi.(Apri Indaya, 2014; Baha et al., 2020; Hendarto, 2011; Kaet, 2019; Ohi, 2019; Sitepu, 2012; dan Utomo, 2017)

Selain tujuan Organologi yang telah diuraikan di atas Organologi memeliliki bidang bidang yang menjadi obyek kajian Organologi. Bidang-bidang yang sering menjadi obyek kajian Organologi adalah: 1) Teknologi bahan alat musik, 2) Teknologi pembuatan alat musik, 3) Teknologi tepat guna alat musik, dan 4) Teknologi perawatan alat musik.

Alat musik merupakan sesuatu yang digunakan untuk menghasilkan suara atau nada untuk membentuk suatu komposisi yang mengandung irama, lagu dan keharmonisan yang mempunyai kesatuan dan kesinambungan. Tongkek adalah salah satu alat musik tradisi yang tumbuh dan berkembang dikalangan masyarakat Pancor. Alat musik ini terbuat dari bahan baku bambu. Tongkek merupakan alat musik pukul berbentuk tabung panjang, terbuat dari bambu yang dipotong pada ruasnya sesuai dengan kebutuhan nada yang dihasilkan.Amir dalam (DR et al., 2014).

\section{METODE}

Jenis penilitian yang digunakan dalam penelitian ini adalah metode deskriptif kualitatif. (L. J. M. Moleong, 2016). Penelitian kualitatif adalah penelitian yang bermaksud untuk memahami fenomena tentang apa yang dialami oleh subjek penelitian misalnya perilaku,persepsi, motivasi, tindakan dan lain-lain. Secara holistik dan dengan cara deskripsi dalam bentuk kata-kata dan bahasa, pada suatu konteks khusus yang alamiah dan dengan memanfaatkan berbagai metode alamiah.

Subjek dalam penelitian ini adalah Pengrajin Tongkek. Teknik pengumpulan data yang digunakan dalam penelitian ini adalah wawancara, uji laboraturium dan dokumentasi. Pemeriksaan keabsahan data dalam penelitian ini menggunakan triangulasi sumber. Triangulasi adalah pengecekan data dari berbagai sumber dengan berbagai cara, dan berbagai waktu. (Arikunto, 2010),(P. D. Sugiyono, 2010), (M. Sugiyono, 2012),(P. D. Sugiyono, 2018), dan (L. J. M. Moleong, 2016) dan Teknik analisis data yang digunakan terdiri dari atas empat tahapan yaitu data collection (pengumpulan data), reduction (reduksi data), Data display (penyajian data), dan Conclusion drawing/verification (pemeriksa kesimpulan dan verifikasi).(John, 2014), (Sugiono, 2017), (P. D. Sugiyono, 2018), dan (L. J. Moleong, 2019).

\section{HASIL DAN PEMBAHASAN}

\section{Proses Pembuatan}

Alat musik Tongkek sumber bunyinya dihasilkan dari badan alat musik itu 
sendiri (idiophone), dan bahan baku utamanya adalah jenis bambu Tereng Jamaq sebutan lokal masyarakat Pancor atau jenis Bambu Ater (Gigantochloa atter (Hssk) Kurz ex Munro). Bambu yang baik digunakan dipilih yang tua dan kering yang rata-rata memiliki kadar air berkisar antara 9,5\% hingga 10,23. hal tersebut telah melalui uji Labolaturium Penguji Balai Pengkajian Teknologi Pertanian (BPTP) NTB pada tanggal 26 Agustus 2018. Pengujian ini mengambil dua buah sample bambu tongkek yang dibuat oleh pengrajin. metode pengujian laboraturium ini menggunakan Metoda Gravime seperti gamabr di bawah ini.

\begin{tabular}{|c|c|c|c|c|c|}
\hline \multirow{2}{*}{\multicolumn{2}{|c|}{$\begin{array}{l}\text { Jenis/Jumlah Contoh } \\
\text { Identifikasi Contoh }\end{array}$}} & \multicolumn{4}{|c|}{ : Jaringan Tanaman (bambu) /2 Contoh } \\
\hline & Ontoh & \multicolumn{4}{|c|}{$:-$} \\
\hline \multicolumn{2}{|c|}{ Tanggal MasukContoh } & \multicolumn{4}{|c|}{ : 24 September 2018} \\
\hline \multirow{2}{*}{\multicolumn{2}{|c|}{$\begin{array}{l}\text { Tanggal Selesai Dianalisa } \\
\text { Hasil Analisa }\end{array}$}} & \multirow{2}{*}{\multicolumn{4}{|c|}{$\begin{array}{l}: 26 \text { Agustus } 2018 \\
: \text { sbb }\end{array}$}} \\
\hline & & & & & \\
\hline \multicolumn{2}{|c|}{ Nomor } & \multirow[b]{2}{*}{ Satuan } & \multicolumn{2}{|c|}{ Hasil Pengujian } & \multirow[b]{2}{*}{ Metoda } \\
\hline Urut & Parameter & & Bambu 1 (belah tipis) & $\begin{array}{c}\text { Bambu } 2 \text { (tanpa } \\
\text { dibelah) }\end{array}$ & \\
\hline 1 & Kadar Air & $\%$ & 10,23 & 9,59 & Gravimetri \\
\hline \multirow[t]{3}{*}{ Ket . } & \multicolumn{5}{|c|}{ 1. Tanggung jawab kami hanya pada ketepatan dan ketelitian hasil analisa dari contoh tersebut diatas. } \\
\hline & \multicolumn{5}{|c|}{ 2. Contoh akan kami simpan selama 1 bulan dari tanggal data analisa ini dikeluarkan } \\
\hline & \multicolumn{5}{|c|}{ 3. Penggandaan dan penyalahgunaan dari data hasil analisis ini diluar tanggung jawab kami. } \\
\hline
\end{tabular}

Gambar 1: Hasil Uji Laboratorium

(Sumber. Dokumentasi Pribadi 2018)

Berdasarkan jenis dan karakteristik yang terdapat pada Tongkek dapat digolongkan ke dalam jenis Idiophones yang dipukul langsung. Mengingat alat musik Tongkek dibuat dengan menggunakan bambu yang dipukul pada tabung resonatornya menggunakan tongkat yang dibuat menggunakan kayu yang berbalut karet dan dipukul langsung untung menghasilkan bunyi.

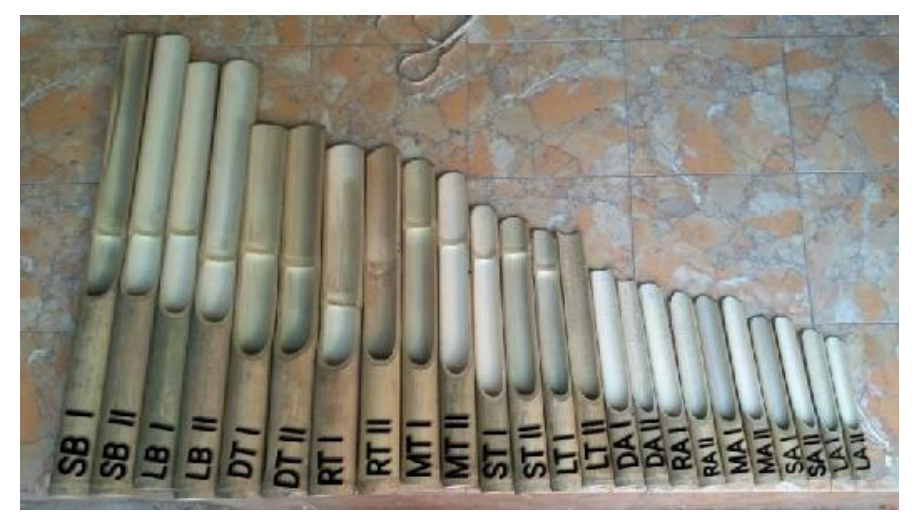

Gambar 2: Dua Set Alat Musik Tongkek

(Sumber. Dokumentasi Pribadi 2018)

Untuk membuat alat musik Tongkek dikerjakan selama kurang lebih 2-4 jam. Sebelum pencarian bahan dasar, terlebih dahulu mempersiapkan alat 
yang akan digunakan untuk membuat Tongkek. Pekerjaan membuat Tongkek merupakan pekerjaan yang membutuhkan ketelitian dan keterampilan yang tinggi untuk menghasilkan kualitas Tongkek yang baik.

Berdasarkan hasil penelitian bahwa alat yang digunakan dalam pembuatan Tongkek merupakan persiapan yang harus dilakukan lebih awal sebelum membuat alat musik Tongkek, sebab jika alat dan bahan yang diperlukan kurang memadai, maka dalam proses pembuatannya tidak maksimal.

Untuk membahas bagian kontruksi Tongkek, peneliti mengacu pada Tongkek buatan Amaq Salim salah seorang empu Tongkek turun-temurun. Instrumen ini memiliki bagian-bagian yang mempunyai fungsi masing-masing, antara lain (1) Badan Tongkek adalah bagian depan dari alat musik Tongkek yang berfungsi sebagai tempat memukul Tongkek pada saat dimainkan, pemukulan yang baik dilakukan pada ujung Parkosan yaitu perbatasan antara tabung suara dan Parkosan.

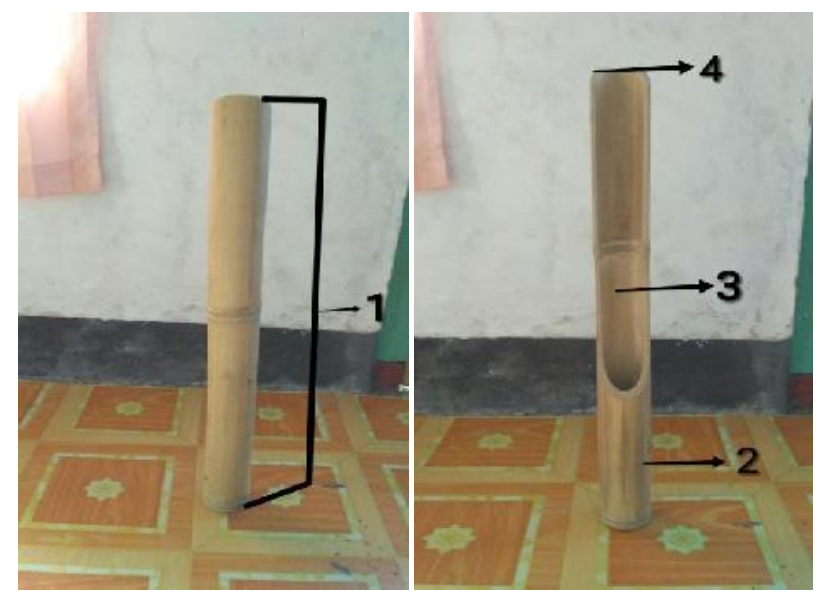

Gambar 3 dan 4: Bagian-bagian Alat Musik Tongkek

(Sumber. Dokumentasi Pribadi 2018)

Keterangan: 1.Badan, 2. Tabung, 3.Parkosan, 4. Ujung.

Pemukul/Pemantok yang digunakan untuk memukul Tongkek disesuaikan dengan diameter dan ketebalan Tongkek, biasanya semakin besar diameter dan ketebalan Tongkek maka semakin banyak lilitan karet, banyak lilitan yang sesuai juga sangat berpengaruh terhadap suara Tongkek nantinya. (2) Tabung Suara adalah bagian teratas pada Tongkek yang berfungsi sebagai penghasil suara pada alat musik Tongkek, dan juga tempat berpegangannya tangan pada saat bermain Tongkek. Pada saat memegang Tongkek usahakan jangan menggenggam bagian tabung karna hal ini dapat mempengaruhi bunyi Tongkek yang keluar, cukup dengan menggunakan bagian ujung dari jari-jari tangan kiri. (3) Parkosan adalah diameter bambu yang dipotong sebagian yang berfungsi membuat nada pada Tongkek menjadi lebih rendah. (4) Ujung Tongkek adalah bagian paling ujung dari Tongkek yang berfungsi membuat nada pada Tongkek menjadi lebih tinggi.

Pada dua set alat musik Tongkek yang terdiri dari 24 Tongkek, memiliki 12 nada yang masing-masing nada terdapat nada yang sama sebanyak dua buah nada yang meliputi Lime Bewek (5), Enem Bewek (6), Sekeq Tengek (1'), Due Tengek (2'), Telu Tengek (3'), Lime Tengek (5'), Enem Tengek (6'), Sekeq Atas (1') , Due 
Atas (2"), Telu Atas (3"), Lime Atas (5") dan Enem Atas (6").

Semakin rendah nada pada Tongkek maka ukuran Tongkek dan panjang tabung semakin panjang, dan sebaliknya jika semakin tinggi nada pada Tongkek maka semakin pendek ukuran dan tabung Tongkek.

Nada yang sama pada Tongkek tidak memiliki ukuran panjang yang sama hal tersebut dipengaruhi oleh diameter bambu dan kedalaman Parkosan, serta panjang tabung, semakin besar diameter bambu maka kedalam parkosan semakin dalam. Tongkek tidak memiliki standar ukuran yang tetap, ukuran Tongkek tergantung pada pembuatnya. Selain itu faktor utama penentu ukuran Tongkek ialah diameter dan panjang bambu yang tersedia.

Alat merupakan salah satu faktor penting dalam pembuatan sebuah instrumen musik secara umum terlebih pada instrumen Tongkek. Peralatan yang digunakan untuk membuat Tongkek diantaranya Pisau yang digunakan ada tiga macam yaitu Timpas, Berang dan Ladek. Alat ini digunakan untuk membelah dan meraut diameter bambu. Pisau yang digunakan haruslah pisau yang tajam. Untuk menajamkannya terlebih dahulu diasah menggunakan batu asah.

Timpas merupakan sejenis pisau parang persegi digunakan untuk membelah diameter bambu yang berukuran besar dan tebal. Hal ini dilakukan karena timpas memiliki ukuran yang lebih besar dari pisau yang lain dan sangat sesuai untuk pemotongan bambu yang berdiameter besar dan tebal.

Berang atau parang digunakan untuk membelah diameter bambu yang tidak begitu lebar dan tebal, hal ini bertujuan agar bambu tidak pecah saat di belah. Ladek berfungsi untuk membelah bambu yang memiliki diameter kecil dan tingkat ketebalan tipis serta meraut tipis diameter bambu yang telah di belah serta meruncingkan ujung Tongkek yang berdiameter kecil.

Gergaji (geregoji) berfungsi sebagai pemotong tanaman bambu menjadi potongan yang sesuai. Palu(Polu) berfungsi sebagai pemukul buku bambu yang tersisa setelah dibelah.

Landesan atau landasan berfungsi sebagai alas agar Tongkek tidak pecah pada saat dipotong dan dibelah.

Amplas yang digunakan adalah amplas yang tidak terlalu kasar agar menghasilkan kehalusan yang baik. Amplas digunakan untuk menghaluskan Tongkek sebelum di vernish (politur).

Thiner berfungsi sebagai bahan pencampur vernish. Pencampuran ini bertujuan agar vernis tidak terlalu kental pada saat dioleskan pada badan Tongkek, karna jika terlalu kental bisa mempengaruhi kualitas suara Tongkek.

Politur Vernis berfungsi sebagai pelapis alat musik Tongkek agar mengkilap dan tahan terhadap rayap. Pelapisan dilakukan pada bagian badan Tongkek, hal tersebut bertujuan untuk membuat warna dari bambu keluar dan mengkilap selain itu juga pelapisan dengan menggunakan vernish bertujuan untuk melindungi badan Tongkek dari goresan dan rayap.

Kuas berfungsi sebagai alat untuk mengoleskan campuran Thiner dan Politur Vernis ke badan Tongkek. Pengolesan dilakukan pada siang hari agar vernis pada badan Tongkek cepat mengering.

Berdasarkan hasil penelitian bahan yang digunakan oleh pengrajin dalam proses pembuatan Tongkek adalah Tereng Jamaq atau Bambu Ater (Gigantochloa Atter (Hassk) Kurz ex Munro).

Sebelum membuat Tongkek maka yang lebih dulu dilakukan adalah mencari 
bahan dasar (Tereng Jamaq), tempat pencarian dilakukan pada penjual bambu yang terdapat di sekitar Lombok Timur, bambu yang dicari adalah bambu yang tua dan memiliki tingkat kekeringan yang sesuai. Bambu yang baik adalah bambu yang tua secara alami, yakni pada saat ditebang pada pohonnya bambu sudah tua. Untuk satu set Tongkek biasanya membutuhkan 3-4 batang bambu.

Setelah bahan baku tanaman bambu didapatkan kemudian tanaman bambu dipotong dengan menyisakan satu ruas bambu, tidak ada ukuran untuk pemotongan tetapi hanya memperkirakan diameternya akan cocok untuk nada apa saja. Dari ujung pangkal sampai ujung atas bambu tidak semuanya bisa digunakan biasanya dari ujung pangkal dipotong 5-7 ruas bambu yang tidak digunakan, biasanya digunakan bambu yang memiliki ketebalan berkisar tidak lebih dari $1 \mathrm{~cm}$ dan tidak kurang dari $0,4 \mathrm{~cm}$. Selain itu juga dipilih bambu yang lurus dan memiliki ruas yang panjang. Semakin tinggi nada yang ingin dibuat maka diameter bambu juga makin kecil. Semakin besar diameter atau semakin panjang tanaman bambu ,maka semakin rendah nada yang bisa dihasilkan dan sebaliknya semakin kecil diameter bambu atau semakin pendek bambu maka semakin tinggi nada yang bisa dihasilkan.

Setelah tanaman bambu dipotong maka selanjutnya tanaman bambu dibelah (Parkos) setengah dari diameter bambu dengan menyisakan setengah dari pangkal ruas bambu sebagai tabung, pencarian dengungan ini dilakukan dengan cara memangkas sedikit demi sedikit mulai dari bawah sampai terus keatas sampai suara dengung keluar. Tidak ada ukuran tetap untuk panjang tabung makin panjang tabung maka semakin rendah nada pada Tongkek dan semakin pendek tabung pada Tongkek maka nada Tongkek semakin tinggi.

Tahap keempat yaitu membuat nada atau melaras/mempout Tongkek. Mempout dalam bahasa Indonesia berarti melaras atau menyetem. Setelah Tongkek dipotong menjadi beberapa bagian dan menghasilkan dengung kumudian nada dicari dengan memotong atau meruncingkan bagian bawah Tongkek untuk meninggikan nada sedangkan untuk merendahkan nada dengan meraut lebih dalam lagi diameter bambu.Setelah dua set alat musik Tongkek selesai dibuat kemudian badan Tongkek diamplas menggunakan amplas yang halus kemudian bagian luar dilapis varnish agar awet dan lebih menarik. Setelah itu Tongkek diangin-anginkan hingga kering.

Pemantok atau pemukul Tongkek terbuat dari bahan kayu yang dibentuk seperti stick sesuai dengan ukuran Tongkek serta dibalut karet dengan lem dan dipasang enjor-enjor/ hiasan rumbai dari bahan benang wol berwarna-warni. semakin besar ukuran diameter dan ketebalan Tongkek maka diameter kayu yang dibentuk semakin besar serta lilitan karet juga semakin tebal. Pemantok terbuat dari tongkat bambu kecil dan stick drum yang dipotong $20-25 \mathrm{~cm}$ dan $10-12 \mathrm{~cm}$ dililit karet bekas ban dalam.

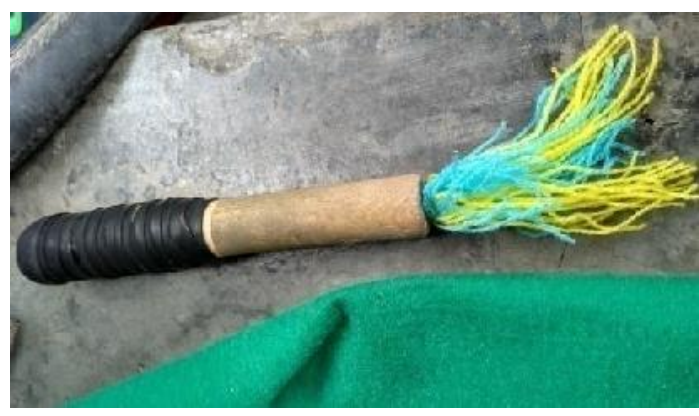


Gambar 5: Pemantok/Alat pemukul Tongkek

(Sumber. Dokumentasi Pribadi 2018)

Setelah bahan ditemukan kayu dipotong dan dibentuk sesuai kenyamanan genggaman tangan dan panjangnya disesuaikan dengan jarak genggaman tangan dengan Tongkek. Setelah kayu dipotong kemudian karet dipotong memanjang agar bisa dililitkan pada bambu. Setelah itu karet dililitkan mulai dari atas kayu sedikit demi sedikit sambil direkatkan dengan lem tiap satu putaran lilitan, tingkat ketebalan lilitan disesuaikan dengan tingkat besarnya diameter bambu dan tingkat ketebalannya semakin besar diameter dan tebal bambu maka semakin tebal lilitan karet. Setelah karet dililitkan pada kayu kemudian benang wol di potong seukuran $10 \mathrm{~cm}$ dengan warna di sesuaikan dengan selera biasanya terdiri dari dua atau tiga warna enjor- enjor ini berfungsi sebagai penghias pemantok.

\section{Proses Penalaan}

Penalaan atau Pelarasan dalam bahasa Sasak lokal Pancor disebut dengan Poutan. Laras yaitu sistem pengaturan frekuensi dan interfal nada-nada (Hendarto, 2011; Isbah \& Wiyoso, 2019; Isbah, 2019; Wisnawa, 2020; Yudarta \& Pasek, 2015). Setelah Tongkek dipotong menjadi beberapa bagian dan menghasilkan dengung kemudian nada dicari dengan memotong atau meruncingkan bagian bawah Tongkek untuk meninggikan nada sedangkan untuk merendahkan nada dengan meraut lebih dalam lagi diameter bambu.

Sistem pelarasan pada alat musik Tongkek menggunakan sistem pelarasan 5 (Lima) nada atau Pentatonis yaitu Slendro $(1,2,3,5,6)$. Nada pada Tongkek dibagi menjadi 3 bagian yakni Nada Bawah /Bewek, Nada Tengah/Tengek dan Nada Tinggi/Atas. Seperangkat alat musik Tongkek terdiri dari 24 instrumen yang meliputi Lime Bewek (5), Enem Bewek (6), Sekeq Tengek (1'), Due Tengek (2'), Telu Tengek (3'), Lime Tengek (5'), Enem Tengek (6'), Sekeq Atas (1"), Due Atas (2"), Telu Atas (3"), Lime Atas (5") dan Enem Atas (6"). Adapun tahapan dalam proses pelarasan atau mempout adalah sebagai berikut:

Pertama yang dilakukan pada saat membuat nada atau mempout Tongkek adalah memotong sebagian diameter bambu, untuk menghasilkan tabung, semakin rendah nada yang ingin dibuat maka ukuran panjang bambu yang dipotong dan tabung yang dibuat semakin panjang, pencarian dengung ini dilakukan sedikit demi sedikit memotong perlahan diameter bambu terus menerus keatas hingga bambu berbunyi nyaring.
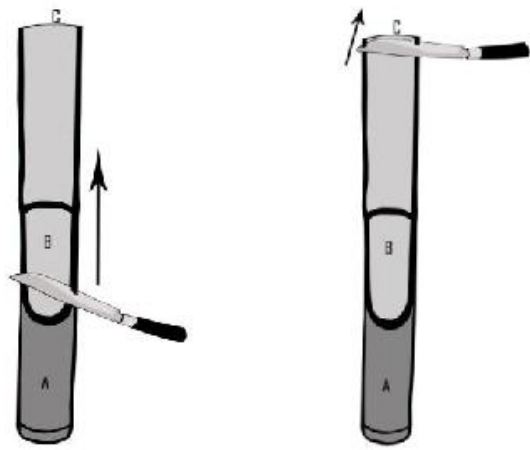

Gambar 6 dan 7: Rautan untuk merendahkan dan meninggikan nada (Sumber. Dokumentasi Pribadi 2018) 
Nada direndahkan dengan memangkas lebih dalam lagi diameter bambu, semakin dalam pangkasan diameter bambu maka semakin rendah nada pada Tongkek, apabila ingin membuat suara Tongkek lebih rendah hendaknya meraut perlahan diameter bambu yang telah dipotong sedikit demi sedikit sampai mencapai suara yang dikehendaki.

Menaikkan nada pada Tongkek dilakukan dengan cara memotong ujung Tongkek, apabila ingin membuat suara Tongkek lebih tinggi, ujung Tongkek diraut perlahan hingga mencapai suara yang dikehendaki. Pada saat menurunkan nada atau menaikkan nada suara Tongkek menjadi tidak keluar atau tidak berdengung maka hal yang harus dilakukan yaitu kembali memangkas tabung jauh lebih atas secara perlahan sampai mengeluarkan suara dengung.

\section{SIMPULAN}

Dalam proses pembuatan alat musik Tongkek, hal terpenting adalah kualitas alat dan bahan yang digunakan untuk membuat Tongkek. Pada saat proses pembuatan Tongkek para pengrajin masih menggunakan tenaga dan keahlianya, mulai dari pemilihan bahan baku, serta alat guna menunjang kualitas Tongkek. Para pengrajin sangat telaten dalam menentukan kualitas suara dan ketahanan Tongkek buatannya.

Proses penalaan Tongkek Bernadakan 5 nada yang berlaraskan Slendro yang terdiri dari 24 instrumen. Dalam proses penalaan hal yang paling pertama dilakukan pengrajin adalah mencari dengung dengan membuat tabung suara kemudian menyesuaikan nada- nada yang dia kehendaki. Proses ini dilakukan mulai dari nada yang paling rendah hingga nada yang paling tinggi. Kualitas suara sangat ditunjang oleh kualitas bahan baku.

\section{REFERENSI}

Apri Indaya, A. (2014). Kajian Organologi Instrumen Perkusi "Cajon" Hasil Produksi Medan Sumatera Utara. Unimed.

Arikunto, S. (2010). Research Procedure a Practical Approach. Jakarta: Rineka Cipta.

Baha, M. A., Murcahyanto, H., \& Imtihan, Y. (2020). Organologi Selober pada Sanggar Selober Pejenengan Desa Pengadangan Pringgasela Lombok Timur. TAMUMATRA: Jurnal Seni Pertunjukkan, 2(2).

Banoe, P. (2003). Kamus Musik. Kanisius.

DR, S., DR, S. S., Savitri, P. R., Gede, I., Raharja, M., Ni Made, P. E., Sang Putu, H. B., Kadek, A. B., Ida Ayu, I. T., \& Ida Ayu, R. W. (2014). Lokalitas Dalam Seni Global IISeminar Seni Nasional Tahun 2014. ISI Denpasar.

Hendarto, S. (2011). Organologi \& Akustika I \& II, Bandung: CV. Lubuk Agung. 
Isbah, M. F. (2019). Kajian Komposisi Dan Aransemen Musik Iringan Kesenian Babalu Di Kecamatan Proyonanggan Tengah Kabupaten Batang. lib.unnes.ac.id. https://lib.unnes.ac.id/34429/

Isbah, M. F., \& Wiyoso, J. (2019). Komposisi Dan Aransemen Musik Babalu Sebagai Sebuah Kajian Musikalitas Tradisional. JURNAL SENI MUSIK. https://journal.unnes.ac.id/sju/index.php/jsm/article/view/28698

John, W. C. (2014). Penelitian Kualitatif dan Desain Riset, Memilih diantara Lima Pendekatan. Yogyakarta: Pustaka Pelajar.

Kaet, M. S. I. (2019). Perubahan Organologi dan Kreativitas Pembelajaran Musik Sasando Di Sanggar Edon Sasando Kupang. Universitas Negeri Semarang.

Moleong, L. J. (2019). Metodologi penelitian kualitatif.

Moleong, L. J. M. (2016). Metodologi Penelitian Kualitatif, cet. ke-35 Bandung: PT. Remaja Rosdakarya.

Ohi, R. (2019). Nilai Organologi Akustik Polopalo. SELONDING, 15(1).

Sitepu, Y. A. S. Y. A. (2012). Organologi Instrumen Tiup Sarune. Grenek Music Journal, 1(1).

Sugiono. (2017). Metode Penelitian Kuantitatif, Kualitatif dan R\&D. Penerbit Alfabeta.

Sugiyono, M. (2012). Metode Penelitian Kuantitatif R\&D. Alfabeta.

Sugiyono, P. D. (2010). Metode Penelitian Pendidikan. Pendekatan Kuantitatif.

Sugiyono, P. D. (2018). Metode Penelitian Kuantitatif,Kualitatif, dan R\&D. ALFABETA, cv.

Utomo, U. (2017). Instrumen Musik Calung Banyumasan: Perubahan Organologi, Kemungkinan Adaptasi Dan Pemanfaatannya Dalam Pembelajaran Seni Musik di Sekolah. osf.io. https://osf.io/preprints/inarxiv/bt9a7/

Wisnawa, K. (2020). Seni Musik Tradisi Nusantara. books.google.com. https://books.google.com/books

Yudarta, I. G., \& Pasek, I. N. (2015). Revitalisasi Musik Tradisional Prosesi Adat Sasak Sebagai Identitas Budaya Sasak. Segara Widya: Jurnal Hasil Penelitian Dan Pengabdian Masyarakat Institut Seni Indonesia Denpasar, 3, 369. 